\title{
LII. Answer to the objections published against a general theory of the visual appearances which arise from the contemplation of coloured objects
}

\section{J. Plateau}

To cite this article: J. Plateau (1839) LII. Answer to the objections published against a general theory of the visual appearances which arise from the contemplation of coloured objects, Philosophical Magazine Series 3, 14:90, 330-340, DOI: 10.1080/14786443908649748

To link to this article: http://dx.doi.org/10.1080/14786443908649748

曲 Published online: 01 Jun 2009.

Submit your article to this journal $[\pi$

Џll Article views: 2

Q View related articles $₫$ 
stance très facile à charbonner, mentioned by Thenard, is probably aldehyd, which from its behaviour towards alkalis might apparently merit that character.

LII. Answer to the Objections published against a general Theory of the Visual Appearances which arise from the Contemplation of Coloured Objects. By J. Plateau, Professor at the University of Ghent.

\section{To the Editors of the Philosophical Magazine and Journal. Gentlemen, Ghent, April 15, 1837. $\dagger$}

I HAVE the honour to transmit you herewith an article 1 which I should thank you to insert in your Journal. Although the main object of this paper is not to make known new facts, you are weil aware that theoretical discussions are not void of interest with regard to science. Besides, when a theory is attacked, it is naturally to the organs of scientific publicity that the office belongs to furnish the author of that theory with the means of defending his ideas. As it was in England that the principal objections against my statements appeared, and as a part of those objections were published in your Journal; lastly, as my article contains a mere scientific defence, I make no doubt, Gentlemen, that you will willingly devote your pages to it, and do me the favour to insert it in your next Number.

$$
\begin{aligned}
& \text { I remain, Gentlemen, yours, \&c., } \\
& \text { JH. PLATEAU, } \\
& \text { Professor at the University of Ghent. }
\end{aligned}
$$

In publishing my theory on the visual appearances which succeed the contemplation of coloured objects, and on those which manifest themselves during that contemplation $\ddagger$, I conceived that if this work deserved any attention, it was principally on account of the generality and simplicity of the point of view under which I have united four different classes of phænomena whose affinity to each other has not been acknowledged; namely, the duration of impressions on the retina, the

$\uparrow$ This communication, as I subsequently learnt from M. Platean, was forwarded from Ghent at the date which it bears, and having, after being long given up for lost, at length come to hand through some unknown channel, it is now published without further delay.-R. $T$.

† See An. de Chim. et de Physique of Messrs. Gay-Lussac and Arago, August 1833, page 386, and April 1835, page 337. Supplement to the Treatise on Light of Sir J. Herschel, by M. Quetelet, page 515. Memoirs of the Academy of Brussels, tom. viii. 
accidental colours by succession, the irradiation, and the accidental colours by simultaneousness, or the effects of the juxtaposition of colours. Above all, I should have thought that if my inquiries had given rise to any refutation, it would have been directed against my general principle, against the law of continuity on which $I$ have made these various phænomena depend: however such has not been the case. It is true, several objections have appeared; but they merely relate to some particular facts, or at most to that class of phænomena which constitute the accidental colours of the first-named species.

Be that as it may, I shall successively examine these different objections; but in order to make them more easily appreciated, it will be necessary first to restate summarily the principles of my theory.

I have divided the appearances in question in two large sections : the first comprehends those which succeed the contemplation of objects; that is to say, the duration of impressions, and the accidental colours by succession, or which show themselves after the disappearing of the objects which produce them. In the second are contained the appearances which accompany the contemplation of objects : that is to say, the irradiation, and the accidental colours by simultaneousness, or which manifest themselves in presence of the objects looked at.

Now, if we consider that the phænomena of the first section are produced from the moment when the object ceases to act upon the retina, to the one in wohich the organ recovers its normal state, and that, on the other hand, those of the second section surround, on the retina, the space directly excited by the light, from the contour of that space to those parts of the organ which remain in their normal state, we may say that the first constitute, in the organ, the passage from the state of excitation to the normal state with regard to time, and that the others constitute the passage from the state of excitation to the normal state with regard to space.

Upon exanining the laws which regulate each of these passages, I have remarked a very striking analogy between them; the one being, as it were, but the translation of the other, by substituting space for time. The facts already known, together with my own observations, have induced me to acknowledge that these laws are as follows.

In the first case, that is, in the passage roith regard to time, the retina being suddenly left to itself after an excitement sufficiently prolonged, retains for some length of time this same state of excitement, which gradually vanishes, to give 
place to a state of nature directly opposite. 'The first of these two effects constitutes the duration of the primitive impression, and the second the apparition of the complementary accidental colour. These are the most manifest effects: but afterwards the impression almost always undergoes oscillations more or less regular: frequently the only effect perceived is the accidental colour which alternately appears and disappears; but in certain circumstances, the accidental colour alternates with recurrences of the primitive colour, so that the impression then passes alternately into troo opposite states, till it completely vanishes.

In the second case, that is, in the passage with regard to space, the state of excitement in the retina extends itself to a small distance round the portion directly excited by the light, and beyond that is manifested a state of nature dircctly opposite, from which results the sensation of the complementary colour. The first of these two phænomena constitutes irradiation, and the other the second species of accidental colours, or the effects, so ably analysed by $\mathrm{M}$. Chevreul, of the juxtaposition of colours. These two principal phænomena are commonly the only ones manifested; but in favourable circumstances, beyond the space occupied by the complementary colour, the primitive colour is again to be found, though much weakened; so that oscillations as to time are here substituted, to a certain degree, by oscillations as to space, if I may be permitted so to express myself.

In order to render the statements of the facts more easy, and to recall the opposition between the primitive and complementary impressions, I have named the first positives, and the second negatives.

Now the discussion of the phænomena of the first section has induced me to make them depend upon the general principle which follows:

When the retina is submitted to the action of the rays of any colour whatever, it resists that action, and tends to recover its normal state, with a gradually increasing,force. Then, if the organ be suddcnly withdrawn from the exciting cause, it returns to the normal state by a sort of oscillatory motion, the more intense as the action has been further prolonged, a motion in virtue of which the impression passes first from the positive to the negative state, and then continues generally to oscillate, in a manner more or less regular, by becoming weaker, until it has entirely vanished.

Hence the successive opposite states of the impression would be analogous to the successive positions of a body removed from a stable equilibrium, and which alternately transports. 
itself from one side to the other of its original position of repose, until its movement be completely annihilated. Besides, as I have said in the publications wherein I have made known my theory, I consider this principle of oscillations as general; that is to say, applicable to any organ whatever, and even to moral phænomena.

With respect to the appearances of the second section, they may be compared to the alternations of the two opposite electricities in an insulated conductor which is submitted to the influence of an electrified body; or likewise to the phienomena which a circular plate presents whose centre is made to vibrate, and in which opposite vibrations are separated by circular lines of repose, \&c.

Thus the phænomena of the first section would be the effects of the same law of continuity and inertia that we see manifested in a great many instances, when a body removed from a state of stable equilibrium is afterwards suddenly left to itself; and those of the second section would be equally the effects of an analogous law of continuity, which is frequently manifested when only a portion of a body is maintained, in one way or other, in a state differing from its normal state.

The foregoing is a summary of my theory of visual appearances. With regard to the series of proofs upon which I have grounded it, I can only refer to the papers already quoted in the note. The first article of the Annales de Chimie et de Physique, as well as the note inserted in the Supplement to the work of Sir J. Herschel, are nothing more than summary expositions of the ensemble of my work; but the memoir contained in the collection of the Brussels Academy, and in the number of April 1835 of the Annales de Chimie et de Physique, is a complete development of that part of my inquiries which relates to phænomena of succession, or of the first section. I am now occupied with the second part of this memoir, that is to say, with that which embraces phænomena of simultaneousness, or of the second section.

We shall now pass to the objections. The first which came to my cognizance were advanced in an anonymous article of the Edinburgh Review (number for April is34, page 160 , and following*.) Unluckily, the anthor had no knowledge of my theory but from the first of the two summary expositions of which I have just spoken, and he was consequently not able to judge of it with thorough competence.

* The reader may consider that my answer has been a long time deferred, but it was only very recently that I knew of the oljections in question. 
His first attack is directed against one of the proofs by which I intend to establish an opposition of nature between accidental and direct impressions. My proposition was thus expressed *:-

"In the cases where the combination of real colours produces rohite, the combination of accidental colours produces the contrary to white, or black. Whereas, for instance, two real complementary colours produce together rehite, two accidental complementary colours produce together black.

"This fact may be ascertained by an experiment: place on a black ground a rectangle of paper, the two halves of which are painted with two complementary colours, for instance red and green, as indicated by the fig. $1 . \dagger$, the middle of each coloured portions being marked with a black point. Then, if you alternately direct your sight from one of these points to the other, for a sufficient length of time, the result will be an image, in the bottom of the eye, formed by the superposition of the accidental green produced by the red half, and of the accidental red produced by the green half; or, in other terms, by the superposition of two complementary accidental colours. Now, if you suddenly and completely cover your eyes with a handkerchief, this image will appear perfectly black, having on the right hand a red image, and on the left a green image (supposing that the green and red halves of the rectangle be placed as in the figure). The production of these two lateral images sufficiently explains itself."

I shall here subjoin some particulars for persons who may wish to repeat the experiment. The rectangle I employed was 90 centimetres long by $10 \mathrm{high}$, and the ground on which I placed it was a large black shawl spread on the floor, in a light room. I stood with my back to the windows, but so as not to throw a shadow on the object. I then directed my sight alternately on the two black points, looking at each of them for nearly a second, and I continued thus about the space of a minute, after which I covered my eyes, as I before said.

These are now the objections. The anonymous author begins by saying that this property of accidental colours advanced by me, must appear, at first sight, an important one, but that a slight examination of the subject will show, " that this proposition is a verbal illusion, and that the physical fact which it so erroneously expresses, has been long known to philosophers."

- Ann. de Chimie et de Physique, August 1833, p. 388.

+ In the figure which accompanies the article, (in the Ann. de Chim.) the green half of the rectangle is on the right, and the red half on the left. 
"An accidental colour," says he in continuation, " is something essentially distinct from a colour produced by the action of direct rays. The rays which produce ordinary colours, can be combined in any proportion we please; and the resulting effect is the sum of the actions of each separate ray upon the retina. Hence all the different colours of the spectrum produce a purely white beam of light; and perfect whiteness may be also produced by two compound colours, one of which is complementary to the other. An accidental colour, however, cannot be added to, or combined with another. When the eye sees an accidental colour, suppose red, the excited part of the retina is insensible to all other rays but those of the accidental colour. If we instantly excite the same portion of the retina with another light, which is an accidental green, and thus render it insensible to red, then the eye will see blackness, not because the accidental red and the accidental green compose blackness, but because the eye has been in succession rendered insensible to the two colours which compose white light itself."

Thus the author founds himself upon the hypothesis which attributes accidental colours to a diminution in the sensibility of the retina, as if that were a demonstrated truth. But I have shown at the beginning of the article against which the objections are directed, that this hypothesis is insufficient to explain the phrnomena. I have stated in proof of it this fact: " that accidental colours are perfectly seen in the most complete obscurity." In fact, in the hypothesis adopted by the anonymous author, the accidental colour, for instance, red, which succeeds the prolonged contemplation of a green object, is explained by saying that the retina fatigued by this continued excitation of green light, loses its sensibility to this light, and is then only affected by the rays which form the complementary red tint. This ingenious theory perfectly explains the phænomenon, when, wishing to see the accidental colour, we cast our eye on a white surface, as is usually practised. For then we can admit that the red rays, which enter into the composition of whiteness, alone act on the retina. But what does that explanation amount to, when applied to the accidental colour seen in a complete obscurity, and when, in consequence, no ray reaches the eye that can give the sensation of the complementary tint? Now it is by placing my eyes in that condition, as above indicated, that $I$ have observed the result of the combination of two accidental colours complementary to each other; and it is precisely in order to render impossible the explanation of the fact by the diminution 
of sensibility of the retina in regard to certain rays, that $I$ have thus made the experiment.

But the anonymous author alleges that an accidental colour cannot be added to, or combined with another. To which I answer by referring him to paragraph 24 of the dissertation of Father Scherffer*, one among the philosophers who have made the greatest researches on the subject of accidental colours, the one precisely who has furnished us with the theory which attributes the phænomena to a partial diminution in the sensibility of the organ. In this paragraph, Scherffer relates direct experiments whereby he convinced himself that the accidental colours combine perfectly well together. If the anonymous author maintains that these experiments can be explained by the diminished sensibility, seeing that Scherffer observed the results of the combination by casting his eye on a white wall, I shall answer that the effects are the same in a complete obscurity, as may be easily ascertained, by substituting for the red and green rectangle of my experiment an orange and green one. Then, if the same process is used, three coloured images will be seen, whose intermediate one will be violet. This inage is the result of the combination of the blue and red accidental colours.

Consequently, accidental colours are really susceptible of combinations, and the resulting tints are the same as in respect to real colours, except the case in which the two composing accidental ones are complementary to each other. In this latter circumstance, since the result is blackness, it appears to me that I have not expressed the fact erroneously, by saying that two complementary accidental colours produce together black, which signifies, if you will, that they mutually destroy each other.

It is difficult for me to conceive how the anonymous author has not paid attention to this circumstance formally expressed in my article, that it is in a complete obscurity $I$ have observed the phænomena. For this is a chief point in my theory of accidental colours, and totally excludes all the explanations which may be founded upon a diminution of sensibility to certain rays. The author thus continues:-

" If Buffon, or Dr. Darwin, or Count Rumford had been asked what would be the effect of exciting the retina in quick succession with all the simple colours of the spectrum, or with two compound colours which compose white light, they would all have immediately answered, blackness. M. Plateau

- Journal of Physics, by Rozier, tcm. xxvi. year 1785, p. 282. 
has therefore, in this part of the inquiry, merely expressed what has been long known, in language physically incorrect, and calculated to convey very erroneous notions on the subject."

Indeed, the philosophers the author speaks of, might bare made the answer he attributes to them (except bowever Buffon, for the theory of the relative insensibility did not appear till a long time after), because they would have supposed that the effect was observed by casting the eye on a white surface. But if they had been asked what should be the effect in a total obscurity, they would doubtless have said that the decision depended on experience. I have therefore not merely expressed what has been long known.

We now come to the other objections.

"Plateau maintains," says the anonymous author, "that after the direct or positive impression of the primitive colour has continued visible for a certain time, and gradually faded away, it is succeeded by the negative impression, or accidental colour. But what is original in his theory he maintains, that after the accidental colour has faded away in its turn, it is succeeded by the primitive colour, this alternation going on till the impression wears away. If we look into the volume already quoted *, we shall see that the only novelty in Plateau's theory is the recurrence of the primitive inpression, and the continued alternation of the two; but we do not thitrk that this recurrence and alternation are established by sufficient evidence; at least, we cannot by any contrivance render it visible. It is certain that the accidental colour disappears and returns, and undergoes other changes; but these changes, we conceive, are not the effect of the primitive impression, or a continuation of a necessary series of changes, of which the primitive impression is the commencement; but the result of subsequent actions upon the retina, which M. Plateau has not been careful enough to detect and analyse. It has been proved, for example, that a pressure upon the retina with the finger changes the accidental colour, and it is asserted by Sir Charles Bell, that if we squint or distort the eye, a vivid impression on the retina instantly disappears, as if it were wiped out. When M. Plateau, therefore, saw the accidental colour change into the primitive, was he sure that there was no pressure made upon the retina by the motion of the eye, or by the involuntary closing even of the eyelids, which is sufficient to produce the observed change? That the changes of colour

* This work is the Treatice on Optics of Sir David Brewster, forming a part of the Cabinet Cyclopæedia, and in which this philosopher has also presented a theory of accidental colours.

plit. Mag. S. 3. Vol. 14. No. 90. May 1839. Z Z 
in question are not regular, and are produced by some irregular influence, may be inferred from M. Platean's own observation, that the alternations of colour do not alroays take place in the same manner, that they vary with the sensibility of the eyes, and particularly with the circumstances under which the experiment is made; and he afterwards remarks, that the regular alternation of the primitive and accidental colour is the effect most frequently observed. Now this additional frequency of one phænomenon in a series is no proof of a regular law; and when we consider how the retina is affected by the state of the stomach, by the pressure of the blood-vessels, which may, in some cases, be an intermitting or an alternating one, we must demand a series of distinct experiments made with the same result, on the eyes of different observers accustomed to the examination of this class of phænomena, and aware of the causes which exercise a disturbing influence, before we can admit the conclusion drawn by M. Plateau."

The anonymous writer is strangely mistaken, if he supposes that $I$ attach any value to the novelty of my experiments. In support of my theory, I should have considered it more advantageous, had I only to relate facts before ascertained. For, with respect to pure phænomena of sensations, more than in any other circumstance, it may be supposed that the author of a theory is influenced in his judgements, in spite of himself, by the desire of reconciling the facts with his system. Accordingly, in my detailed memoir, I have endeavoured, as much as possible, to establish my statements on anterior observations; and, when this resource failed me, I was most careful in requesting other persons to repeat my experiments. For instance, with respect to the recurrence of the primitive impression, a recurrence that the anonymous author was not able to observe, I have quoted, in my memoir, the following experiment related by Rozier, the editor of the Journal of Physics*:

"Suppose," says he, " any apartment, either deprived of the sun's light, or at least in the moment when it can be said that it is neither day or night (the experiment succeeds better in the first case). Suppose in this apartment a candlestick furnished with a lighted wax taper; the light of a candle or lamp producing the same effect. Place this candlestick at your feet, on the floor; look at this light perpendicularly, so that your eyes remain fixed on it without interruption for several moments. Immediately after, place an extinguisher on this light, lift up your eyes to the wall of the apartment, fix

* See this Journal, tom. vi. page 486, year 1775 . 
your sight towards the same point, without winking the eye; you will see nothing but darkness at the beginning of this operation, after that, towards the point you look at, there will appear a much greater obscurity than that of the remainder of the apartment. Continue thus to keep your sight steadily fixed; gradually in the middle of this obscurity, a reddish colour will manifest itself; it roill become insensibly enlivened, its brightness will increase, and at last it will acquire the colour of the flame."

Thus, in this experiment, the obscure negative image, that is to say, contrary to the brilliant impression of the flame, was gradually changed into a new luminous image having the colour of this flame; that is, into a positive image. I must here remark, that Rozier recommends to fix the sight torwards the same point without winking the eye, and further, to keep the sight steadily fixed, so that these precautions remove every supposition of pressure or distortion of the eyes, which could alone, as the anonymous author maintains, cause the image to vary. I shall add, that this experiment has not been made with the view of giving weight to any theory; Rozier presents it simply as a fact that he does not seek to explain. With respect to more multiplied alternations of the two impressions, alternations which the anonymous author has not been more successful in verifying, unluckily no one, as far as I know, had noticed them before me. For which reason 1 have taken care to associate other persons with myself, who have experienced the same effects, and I have cited among them $M$. Quetelet, a name which ought to inspire the fullest confidence (see my article of Annales, page 392). I will here relate the experiment such as $I$ describe it in that article, pages 393 and 394 .

"I applied to one of my eyes a black tube about 50 centimetres long by 3 in diameter, at the same time covering the other eye completely with a handkerchief, and I looked steadfastly, during a minute at least, on a red paper exposed to a clear day-light; after which, withdrawing the tube suddenly without uncovering the other eye, I looked at the white ceiling of the apartment. I then saw a green circular image, which, after some time, gave place to a red one of a feeble intensity indeed, and of a very short duration, but perfectly visible; afterwards, the green colour reappeared, which, soon after, was again succeeded by a reddish image, and thus three or four times successively, the two opposite impressions being less and less intense."

I shall only subjoin that the coloured paper ought to be sufficiently large for its edges not to be perceived. In this Z 2 
experiment I have seen as many as nine oscillations of the impression produced, that is to say, five transitions from the positive to the negative, and four from the negative to the positive. With regard to disturbing causes which might, according to the anonymous author, have occasioned these modifications in the impression, I must, if such had presented themselves, have been a very unskilful observer, not to have noticed their influence, nor have secured myself against them. I must moreover say that with respect to myself the accidental colours are not so fugitive, and that they by no means disappear from my eyes by distorting them, squinting, or closing the eyelids.

The anonymous author is again mistaken, in attributing to me this assertion, that the regular alternation of the primitive and accidental colour is the effect most frequently observed. I have, on the contrary, said (page 392 in the article of the Annales), that the effect most frequently observed was that of the disappearances and reappearances of the negative or accidental impression alone. And indeed, among the philosophers who have made researches on accidental colours, many have taken notice of this fact, as, for instance, may be seen in the memoirs of Scherffer and Darwin.

'The reader may see from what precedes, that the facts I have advanced are not deficient in authority, as the anonymous author seems to allege; he has there limited his objections; let us, therefore, proceed to those which have been raised by other persons.

[To be continued.]

LIII. On the Constitution of the Resins. By Jamrs F. W. Johnston, Esq. F.R.S., Professor of Chemistry and Mineralogy in the University of Durham.

\section{To Richard Phillips, Esq.}

My dear Philitips.

Durham, March 20, 1839.

$\mathbf{T}$ HE more I study the constitution of the resins the more interesting does it become ; and I begin now to consider them as presenting one of the most beautiful natural families to be met with in the entire range of organic chemistry. In my last letter I gave you an outline of some of the results at which I had then arrived. You will be interested probably in learning the further development I have already been able to give them. This will best appear by presenting to you an outline of the classification of the resins, so far as they have yet been analysed.

$$
\text { General Irrational Formula }=\mathrm{C}_{40} \mathrm{H}_{32+x} \mathrm{O} y
$$

